\title{
An Uncommon Cause of Pathological Fracture: Tenofovir-induced Osteomalacia and acquired Fanconi's Syndrome in a Retroviral Patient
}

\author{
${ }^{1}$ Shivaram R Komandla, ${ }^{2}$ Naresh K Monigari, ${ }^{3}$ Muralidhar V Danturulu, ${ }^{4}$ Sudha Vidyasagar
}

\begin{abstract}
Here we report a 60 -year-old female patient with retroviral illness on antiretroviral therapy with tenofovir/emitricitabine/ efavirenz since 4 years, who presented with fracture of the right 4th metatarsal and bone pains and was found to have hypophosphatemia with normal vitamin D, calcium, and parathormone levels. Further testing revealed elevated serum creatinine, phosphaturia, uricosuria, glycosuria, and metabolic acidosis supporting the diagnosis of Fanconi syndrome. Adverse drug reaction was suspected as the patient was on tenofovirbased regimen. Hence, it was stopped and, subsequently, oral phosphate supplementation was given. Patient improved after discontinuation of drug, confirming tenofovir as a cause of Fanconi syndrome. Serum phosphorous level returned to normal after 3 months of discontinuation of tenofovir. On follow-up, patient's phosphorous level was $3.2 \mathrm{mg} / \mathrm{dL}$ and oral phosphorous supplementation was stopped. This case shows the need for screening of proximal tubular function (serum creatinine, vitamin D levels, urine-phosphate, protein, and sugars). Usually tenofovir toxicity is reversible upon discontinuation of drug, but if toxicity goes unrecognized, prolonged usage of drug can cause irreversible tubular damage.
\end{abstract}

Keywords: Fanconi's syndrome, Hypophosphatemia ,Tenofovir.

How to cite this article: Komandla SR, Monigari NK, Danturulu MV, Vidyasagar S. An Uncommon Cause of Pathological Fracture: Tenofovir-induced Osteomalacia and acquired Fanconi's Syndrome in a Retroviral Patient. J Postgrad Med Edu Res 2016;50(3):156-158.

Source of support: Nil

Conflict of interest: None

\section{INTRODUCTION}

Tenofovir in view of favorable side effect profile is being used more frequently than before for treatment of HIVinfected patients. As per the World Health Organization (WHO) guidelines, tenofovir-based regimen is considered as first-line treatment for retro viral illness. In such a

\footnotetext{
1,2 Junior Resident, ${ }^{3}$ Associate Professor, ${ }^{4}$ Professor and Head

${ }^{1-4}$ Department of General Medicine, Kasturba Medical College Manipal, Karnataka, India

Corresponding Author: Naresh K Monigari, Junior Resident Department of General Medicine, Kasturba Medical College Manipal, Karnataka, India, Phone: +917760597347, e-mail: medico.ktya@gmail.com
}

scenario, better understanding of adverse drug reactions and prompt recognition of the toxicity is necessary to prevent development of full-blown Fanconi syndrome.

\section{CASE REPORT}

A 60-year-old female patient was diagnosed with retro positive illness in 2005 with CD4 count- $62 \times 106$ cells/L and HIV viral load of $<20$ copies/mL was being treated with lamivudine, stavudine, and nevirapine till 2008. In 2008, owing to the immunological failure (CD 4 count decreased from 250 to $150 \times 106$ cells/L) and virological failure (HIV viral load $>1000$ copies $/ \mathrm{mL}$ ), her antiretroviral therapy (ART) was modified to tenofovir (300 mg), emitricitabine (200 mg), efavirenz (600 mg)based regimen, which she continued for 4 years. She was compliant with medications and her CD4 count showed significant improvement (CD4 count was $792 \times 106$ cells $/ \mathrm{L}$, HIV viral load $<30$ copies/mL in 2012). Patient was on modified ART for 4 years and during follow-up presented with pain in right foot since 3 days and generalized body ache and bone pain of 5 months' duration, with no history of trauma to right foot. Examination showed tenderness and swelling over right foot, with systemic examination being within normal limits.

\section{INVESTIGATIONS}

X-ray image of the right foot showed osteopenia with undisplaced fracture of right 4th metatarsal (Fig. 1). Chest X-ray showed decreased bone density in spine. Dual energy X-ray absorptiometry scan showed " $\mathrm{T}$ " score of -1.5 at lumbar spine low for her age, 0 suggestive of low bone mineral density. Serum phosphorous level was low at $1.6 \mathrm{mg} / \mathrm{dL}(2.4-4.7)$ with normal vitamin D level $40.42 \mathrm{ng} / \mathrm{mL}$ (>30), normal calcium $9.3 \mathrm{mg} / \mathrm{dL}$ (8.9-10.3), and normal parathormone level $29.68 \mathrm{pg} / \mathrm{mL}$ (15-65) narrowing the differential diagnosis. Isolated alkaline phosphate level elevation was present $234 \mathrm{U} / \mathrm{L}$ (50-140). Additional investigation showed significantly deranged serum creatinine $1.6 \mathrm{mg} / \mathrm{dL}(0.5-1.2)$, low uric acid levels $1.5 \mathrm{mg} / \mathrm{dL}(2.5-6.5)$, hypokalemia $3 \mathrm{mmol} / \mathrm{L}$ (3.6-5.1), protenuria 2 with 24 hours protein $500 \mathrm{mg}$, glycosuria 2 in presence of normal blood glucose $108 \mathrm{mg} / \mathrm{dL}$, phosphaturia, aminoaciduria, and uricosuria, 


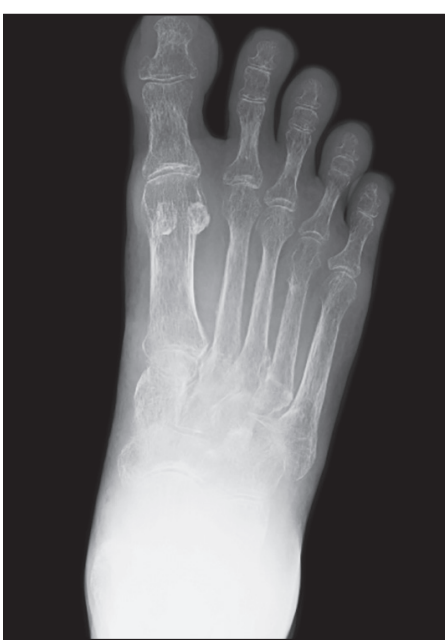

Fig. 1: X-ray of the right foot showing osteopenia with undisplaced fracture of right 4th metatarsal

suggestive of proximal renal tubular dysfunction (Fanconi syndrome). Molecular testing could not be done as the patient could not afford. Metabolic acidosis was found on arterial blood gas analysis ( $\mathrm{pH} 7.24, \mathrm{CO}_{2} 23 \mathrm{~mm} \mathrm{Hg}$, $\mathrm{HCO}_{3}-12 \mathrm{mmol} / \mathrm{L}$ ) with normal venous lactate levels $3.9 \mathrm{mg} / \mathrm{dL}$ (5-22). Tubular reabsorption of phosphate was low (0.38).

\section{DIFFERENTIAL DIAGNOSIS}

Osteomalacia and pathological fracture in a retroviral illness patient can be caused by vitamin D deficiency and hyperparathyroidism; these were ruled out in our patient. Uncontrolled HIV infection by itself can cause these symptoms, but in our patient as HIV infection was under control with tenofovir therapy (CD count $792 \times 106$ cells/L, and HIV viral load $<30$ copies $/ \mathrm{mL}$ ) cannot be substantiated as the cause for the same.

\section{Treatment}

Tenofovir was stopped and patient was started on phosphorous and calcium supplements.

\section{Outcome and Follow-up}

Follow-up after 3 months showed normal serum creatinine and serum phosphorous, and urine analysis showed absent sugar, protein, and amino acids.

\section{DISCUSSION}

Tenofovir belongs to nucleoside reverse transcriptase inhibitor exhibiting nephrotoxicity by effecting proximal tubular cell function. Tenofovir is the least toxic of the nucleoside reverse transcriptase inhibitor group and the only accepted drug for treatment of HIV infection. ${ }^{1,2}$ Tenofovir is eliminated from body primarily by proximal tubular secretion and glomerular filtration. ${ }^{2}$ Multivariate analysis showed low body mass index, advanced age, and low CD4 count as predictors for risk of development of nephrotoxicity in tenofovir-treated patients. ${ }^{3}$ Low body weight noted in our patient may be one predisposing factor for the development of tenofovir-induced renal dysfunction. Nucleoside phosphonates cause nephrotoxicity by accumulating in renal tubular cells. Tenofovir entry into cell is mediated by Hoat1, which is a transporter on basolateral membrane of proximal tubule and into the urine through multidrug-resistant protein (MRP2), which is located on the apical side of the proximal tubule cell. This luminal efflux is probably the ratelimiting step in tubular secretion pathway. The frequency of nephrotoxicity increases significantly if a patient is on protease inhibitors as they inhibit MRP-2 without effect on hoat1 transporter, thereby increasing intracellular tenofovir drug concentrations. ${ }^{4}$ As per the present data, onset of renal dysfunction usually occurs within 1 to 26 months of starting of tenofovir, ${ }^{5}$ rare cases were reported with onset of renal dysfunction 6 years after starting of tenofovir. ${ }^{6}$ The onset of symptoms (myalgia and bone pain) in our patient was noticed after 34 to 36 months of tenofovir therapy. Biochemical investigations showed hypophosphatemia; hypouricemia; hypokalemia with normal calcium, vitamin $\mathrm{D}$, and parathormone levels; and mild renal dysfunction. Urine analysis showed proteinuria and phosphaturia with significantly reduced tubular reabsorption of phosphate $(0.38 \mathrm{mg} / \mathrm{dL})$, aminoaciduria and glycosuria in presence of normal blood glucose. Arterial blood gas analysis of the patient showed acidosis with low bicarbonate levels, normal lactate levels, and high serum chloride. With earlier biochemical evidence and previous literature showing association of tenofovir and renal dysfunction, ${ }^{7}$ a diagnosis of acquired Fanconi's syndrome was made, with the most probable etiology in our patient being adverse drug reaction due to tenofovir. Casualty assessment of adverse reaction was done using WHO-UMC (Uppsala Monitoring Centre) and Naranjo Scale both algorithms labeled tenofovir as "Probable." Severity of adverse drug reaction was level 4 (moderate) on Hartwig's Severity Assessment Scale. Hypophosphatemia due to acquired Fanconi's syndrome probably caused stress fracture and osteomalacia in the patient. Even though previous case reports showed the role of vitamin D deficiency in osteomalacia caused by tenofovir, our investigations showed otherwise. ${ }^{8}$ Our patient had asymptomatic isolated elevation of alkaline phosphatise levels and mild proteinuria before the development of clinical features suggestive of osteomalacia (myalgias, bone pains, and stress fractures). ${ }^{9}$ In view of the reversible nature of the condition, renal biopsy was 
not performed. Patient's stress fracture was treated with immobilization in plaster cast for 1 month. Tenofovir was discontinued and patient was started on calcium and phosphorous supplementation. On follow-up after 3 months, the patient's symptoms improved, serum phosphorous was $3.8 \mathrm{mg} / \mathrm{dL}$, and serum creatinine became normal $(1 \mathrm{mg} / \mathrm{dL})$. This case highlights the importance of frequent testing for creatinine, serum phosphorous periodically, as per clinicians' perspective as no guidelines have been issued by the WHO. It is essential to monitor serum creatinine, serum phosphorous, urine proteinuria, phosphaturia, and glycosuria for early diagnosis.

Early recognition will help to discontinue the drug before irreversible tubular damage occurs.

\section{REFERENCES}

1. Kapadia J, Shah S, Desai C, Desai M, Patel S, Shah AN, Dikshit RK. Tenofovir induced Fanconi syndrome: a possible pharmacokinetic interaction. Indian J Pharmacol 2013 Mar-Apr; 45(2):191-192.

2. Fernandez-Fernandez B, Montoya-Ferrer A, Sanz AB, Sanchez-Niño MD, Izquierdo MC, Poveda J, Sainz-Prestel V, Ortiz-Martin N, Parra-Rodriguez A, Selgas R, et al. Tenofovir nephrotoxicity: 2011 update. AIDS Res Treat 2011;2011: 354908 .
3. Nelson MR, Katlama C, Montaner JS, Cooper DA, Gazzard B, Clotet B, Lazzarin A, Schewe K, Lange J, Wyatt C, et al. The safety of tenofovir disoproxil fumarate for the treatment of HIV infection in adults: the first 4 years. AIDS 2007 Jun 19;21(10):1273-1281.

4. Rollot F, Nazal EM, Chauvelot-Moachon L, Kélaïdi C, Daniel N, Saba M, Abad S, Blanche P. Tenofovir-related Fanconi syndrome with nephrogenic diabetes insipidus in a patient with acquired immunodeficiency syndrome: the role of lopinavir-ritonavir-didanosine. Clin Infect Dis 2003 Dec;37(12):e174- e176.

5. Williams J, Chadwick DR. Tenofovir-induced renal tubular dysfunction presenting with hypocalcaemia. J Infect 2006 Apr;52(4):e107-e108.

6. ShkendieV, Irida H, TauseefS, Muhammad Umer A,PadminiM. Acute renal failure and Fanconi's syndrome in an HIV patient treated with tenofovir. Int J Collab Res Intern Med Public Health 2012;4(5):850-853.

7. Izzedine H, Launay-Vacher V, Isnard-Bagnis C, Deray G. Drug-induced Fanconi's syndrome. Am J Kidney Dis 2003 Feb;41(2):292-309.

8. Lucey JM, Hsu P, Ziegler JB. Tenofovir-related Fanconi's syndrome and osteomalacia in a teenager with HIV. BMJ Case Rep 2013 Jul 9;2013.

9. Tjen-A-Looi A, Naseer SN, Worthing AB, Timpone JG, Princy NK. Hypophosphatemic osteomalacia associated with tenofovir use in HIV infected patients: a case series and review of the literature. J AIDS Clin Res 2012;S4:008. 